\title{
LA FALTA DE REGULACIÓN DEL STALKING EN CHILE: EL ROL PROTECTOR DE LAS CORTES DE APELACIONES*
}

\section{THE LACK OF STALKING REGULATION IN CHILE: THE PROTECTIVE ROLE OF THE COURTS OF APPEALS}

\author{
EdMUNDO JAVIER Borel ReY ${ }^{* *}$
}

\begin{abstract}
RESUMEN: En la causa Rol No 2261-2018, la Corte de Apelaciones de Valdivia rechazó un recurso de protección por encontrarse los actos atentatorios a la honra alegados por la recurrente siendo conocidos en una causa penal por injurias. Sin embargo, la recurrente también daba cuenta de una serie de otros actos de acoso psicológico como merodeos de su domicilio, llamadas y mensajes reiterados, de los que la Corte no se hizo cargo. En Chile la víctima no puede detener estos actos por la vía penal pues no existe tipificación de lo que en Derecho Comparado se conoce como "stalking", dejando la Corte sin protección a la recurrente frente a actos que alteran el normal desarrollo de la vida cotidiana, vulnerando derechos fundamentales.
\end{abstract}

Palabras clave: Stalking, integridad psíquica, vida privada, libertad de autodeterminarse.

ABSTRACT: In Case No 2261-2018, the Court of Appeals of Valdivia rejected a constitucional protection action because the dignity-threatening acts adduced by the appellant were being known in a criminal case about defamation. However, the appellant also reported a series of other psychological harassment acts such as loitering, repeated calls and messages, which the Court did not address. In Chile, the victim cannot stop these acts through criminal procedure, since what is known in Comparative Law as 'Stalking' has not been criminally regulated. Thereby, the Court left the appellant unprotected against acts that alter the normal development of daily life, violating constitutional rights.

Key words: Stalking, psychic integrity, private life, freedom of self-determination.

\section{INTRODUCCIÓN}

La Corte de Apelaciones de Valdivia, en causa Rol No 2261-2018, rechazó un recurso de protección que merece especial atención. La recurrente alegó que llevaba meses siendo víctima de actos de hostigamiento psicológico de parte de la cónyuge de su pareja, quienes estaban separados de hecho. La recurrida no solo habría publicado en internet comentarios vilipendiosos contra la recurrente sino que además habría ejercido constantes actos de acoso como merodear su domicilio, utilizar fotos, de la recurrente en su whatsapp, y llamarla y mandarle mensajes reiterados tanto a ella como a su pareja. La recurrente solicitó a la Corte que ordenara a la recurrida tanto la eliminación de las publicaciones injuriosas como el cese de los demás actos de acoso e invasión a su vida de pareja.

* Este artículo contó con una versión digital previa que se reemplazó por la que aquí se ofrece. La nueva versión eliminó los nombres y apellidos de las partes intervinientes, además de hacer correcciones menores

** Abogado. Licenciado en Ciencias Jurídicas y Sociales de la Universidad Austral de Chile. Dirección postal: Villavicencio No 361, oficina 110, comuna y ciudad de Santiago, Chile. Dirección electrónica: eborelr@gmail.com. 
Las aristas fácticas de este caso merecen especial atención al guardar coincidencia con determinados comportamientos constitutivos de lo que se denomina stalking en el Derecho Comparado. Estos comportamientos tienen en Chile un flanco jurídico abierto que llama la atención desde que se trata de un fenómeno que no es inocuo, encontrándose tipificado penalmente en otros países, adoptando múltiples manifestaciones, además de guardar estrecha relación con la violencia de género y el cyberbullyng.

Ante la ausencia de regulación penal de este tipo de comportamientos acosadores $y$, en consecuencia, la poca utilidad de denunciar ante Carabineros de Chile, este trabajo pretende dar cuenta de cómo el recurso de protección puede resultar una herramienta útil para las desprotegidas víctimas, al vulnerarse patentemente determinados derechos fundamentales. Sin embargo, la falta de entendimiento de este fenómeno, producto tanto de su falta de regulación como de su falta de tratamiento por parte de la doctrina, puede llevar a las Cortes de Apelaciones a no visualizar el stalking como un comportamiento dañino en sí mismo, o a diluirlo en otro tipo de conductas reguladas que en realidad no son lo mismo, terminando por rechazar recursos de protección como el que se analizará.

Las Cortes de Apelaciones deben tener claro que los hechos alegados en el caso que se revisará son constitutivos de un comportamiento que, sin perjuicio de no estar regulado en Chile, sí tiene contornos y definición propia. Por otro lado, si bien es cierto que no todo comportamiento humano dañino se encuentra tipificado penalmente, no por ello esas conductas dejan de afectar derechos fundamentales, por lo que las Cortes no pueden olvidar su rol tuitivo por medio del Recurso de Protección que muchas veces se vuelve la única herramienta para afrontar situaciones jurídicamente no reguladas.

\section{FALLO DE LA CORTE DE APELACIONES DE VALDIVIA, ROL 2261-20181}

\section{Los hechos Que fundan el Recurso de Protección}

El 18 de diciembre de 2018, doña N. L. deduce Recurso de Protección en contra de la señora M. E., cónyuge de la pareja de la recurrente, don J. O. El señor J. O. y la recurrida se encuentran separados de hecho hace más de dos años y tienen hijos en común. Los hechos que fundan el recurso consisten en supuestos actos de violencia psicológica y hostigamiento constante acaecidos desde abril del año 2018. Se mencionan los siguientes: ir a buscar a la recurrente a su domicilio y al no encontrarla, hacerse pasar por otra persona, entablando comunicación tanto con la guardia del condominio como con la madre de la recurrente con el objeto de obtener información personal de ella y, al mismo tiempo, difamarla; enviar mensajes de whatsapp tanto a la recurrente como a su pareja con claras demostraciones de celos e insultos; rondar el domicilio de la recurrente y vigilarla; llamar por teléfono a la recurrente indicándole que va a meter preso al señor J. O. si la recurrente o sus padres le hacen algo a los hijos; utilizar en su whatsapp fotos de la recurrente que

\footnotetext{
1 Todos los antecedentes aquí expuestos pueden revisarse en sistema de Consulta Unificada de Causas del Poder Judicial, disponible en http://www.pjud.cl/consulta-unificada-de-causas, ingresando el ROL 2261-2018 de la Corte de Apelaciones de Valdivia.
} 
descargó de sus redes sociales²; publicar en la plataforma OIRS del Hospital Base de Valdivia (lugar de trabajo de la recurrente y su pareja el señor J. O.) un reclamo por medio del cual indica que es la recurrente la que la llama insistentemente y le manda mensajes, que el señor J. O. se encuentra en un proceso penal por violencia intrafamiliar, y que es una inmoralidad de parte de la recurrente el tener una relación con un hombre casado y subir fotos de su relación a redes sociales; publicar en la página de Facebook del mismo Hospital comentarios alusivos a la formalización por actos de violencia intrafamiliar de parte del señor J. O. ${ }^{3}$ y aludir que es la recurrente quien la ofende por redes sociales.

Ante este escenario, con fecha 17 de noviembre de 2018 la recurrente publica en $\mathrm{Fa}$ cebook un llamado de alerta a sus contactos sobre lo que pueda decir doña M. E., señalando que lleva meses hostigándola y acosándola. Producto de lo anterior, la recurrida se querella contra la recurrente el día 10 de diciembre de 2018 por el delito de injurias graves hechas por escrito y con publicidad. A la fecha de interposición del Recurso de Protección, la recurrente se encontraba citada a audiencia en procedimiento simplificado fijada para el 18 de enero de 2019, en causa Rol No 7724-2018 del Juzgado de Garantía de Valdivia.

Culmina el relato de los hechos la recurrente señalando que hasta la fecha de interposición del Recurso de Protección, los mensajes y llamadas privadas tanto a ella como a su pareja y las publicaciones burlescas y denigrantes en redes sociales no habían cesado.

\section{El DeRECHO INVOCADO y PETICIONES}

La recurrente invoca como vulnerado el derecho a la honra consagrado en el artículo 19 No 4 de la Constitución Política de la República (en adelante abreviada como "CPR"), derecho que a su juicio se ve afectado desde que la recurrida estaría intentando destruir el prestigio e imagen que la recurrente tiene ante sus compañeros de trabajo, su familia y la comunidad en general.

Por lo anterior, la recurrente solicita a la Corte dos cosas: primero, que se ordene a la recurrida eliminar las publicaciones y comentarios de Facebook, y segundo, que se le ordene abstenerse de realizar cualquier acción de acoso, injuria o burla, mandar mensajes privados y entorpecer su relación sentimental.

\section{Descargos de la RECURRIDA}

$\mathrm{Al}$ evacuar su informe la recurrida solicita se declare la extemporaneidad del recurso, ya que el último acto que se puede considerar para el cómputo del plazo es del 10 de octubre de 2018 (la publicación en Facebook alusiva a los actos de violencia intrafamiliar en los cuales se encontraba involucrado el señor J. O.), aduciendo que las acciones legales por ella

\footnotetext{
2 Ante este episodio, la recurrente toma contacto con la recurrida y le dice que deje de utilizar sus fotos, lo cual genera que la recurrida denuncia de amenazas a la recurrente en la fiscalía local de Temuco, generándose causa ordinaria Rol No 6471-2018 llevada ante el Juzgado de Garantía de Temuco. La causa no progresa por no ser los hechos denunciados constitutivos de delito, como puede verificarse de la resolución de aprobación que da el juez a la decisión del Ministerio Público de abstenerse de investigar, en E. CON L. (2018).

3 El señor J. O. fue absuelto de supuestos actos constitutivos de violencia intrafamiliar según sentencia de 9 de agosto de 2018, en E. CON O. (2018).
} 
ejercida no pueden considerarse para el cómputo del plazo por tratarse del ejercicio legítimo de un derecho.

También señala que los antecedentes esgrimidos por la recurrente son falsos o se han formulado tergiversando la realidad, ya que es la recurrente quien se comunica con ella y la insulta, lo que motivó a deducir querella por injurias en su contra. Agrega que los conflictos con su cónyuge se generan con ocasión de actos de violencia intrafamiliar que dieron lugar a los procesos judiciales que indica.

\section{El ReCHAZO de la CORTE}

Con fecha 14 de enero de 2019, la Corte de Apelaciones de Valdivia dicta sentencia rechazando el Recurso de Protección en base a los siguientes argumentos:

“4.-: Que, en este caso, es claro que existe un conflicto entre la recurrente y recurrida, en el contexto de la relación que mantiene la primera con el actual cónyuge de la segunda, encontrándose estos últimos en un proceso de divorcio, situación que ha producido una peculiar situación de tensión y agresión recíproca, que ha determinado la existencia de un proceso penal, con el objeto de determinar la existencia del delito de injurias graves con publicidad, incoado con ocasión de la querella interpuesta por la señora M. E.

4.- Que, en ese contexto, y encontrándose los hechos sometidos al conocimiento de un tribunal competente quien determinara la existencia o no de los hechos que se han planteado en la causa, su origen y la responsabilidad correspondiente, con las garantías procesales correspondientes, solo cabe desestimar el recurso de autos" ${ }^{4}$.

Por lo anterior, la Corte considera innecesario pronunciarse acerca de la extemporaneidad del recurso y rechaza el recurso de protección, sin costas.

\section{ACTOS RECURRIDOS CONSTITUTIVOS DE STALKING}

Para comenzar, se debe efectuar una distinción respecto a los hechos en los que la recurrente funda su recurso de protección. Por un lado, la recurrente alegó haber sido víctima de publicaciones por redes sociales y un reclamo ante el Hospital Base de Valdivia, actos por medio de los cuales la recurrida habría buscado enlodar su imagen. Respecto a estos actos, que de haber sido efectivos podrían calificarse de injurias, la recurrente requiere a la Corte que se ordene a la recurrida eliminar dichas publicaciones. Pero por otro lado, la recurrente describió haber sido víctima de una serie de otros actos como llamadas, mensajes reiterados y merodeo del domicilio, actos que cuadran con lo que a continuación procederá a explicarse con el nombre stalking. Respecto a este tipo de actos, la recurrente pidió a la Corte ordenar que la recurrida cese toda otra acción de acoso, mensajes, y deje de entorpecer su relación de pareja, ello como petición aparte de que se ordene a la recurrida borrar las publicaciones de Facebook.

\footnotetext{
${ }^{4}$ L. CON O. (2019). Cabe precisar que la transcripción ha sido textual, habiendo la Corte incurrido en la errónea repetición del número $4^{\circ}$ al enumerar los considerandos.
} 


\section{Concepto y características del stalking en Derecho Comparado}

El concepto de stalking es un sustantivo de origen anglosajón proveniente del verbo "stalk" que traducido al español alude a la acción de acechar, caminar sigilosamente, o la observación de la presa por parte del cazador 5 . Como fenómeno social, el stalking se entiende como un patrón de amenaza o acoso anormal o de larga duración dirigida específicamente a un individuo ${ }^{6}$. En palabras de Purcell, Pathé y Mullen "stalking is a course of conduct in which one individual inflicts on another repeated unwanted intrusions and communications, to such an extent that the victim fears for his or her safety" 7 . Westrup y Fremouw señalan como características básicas del stalking las siguientes: i) una conducta repetitiva dirigida contra alguien, ii) la conducta no es bienvenida ni deseada por la víctima, iii) una experimentación de miedo, ansiedad o preocupación por parte de la víctima ${ }^{8}$.

Entre las diversas manifestaciones que puede adoptar este comportamiento se pueden mencionar las siguientes: perseguir, merodear, vigilar, esperar a la víctima en lugares, aproximarse y comunicarse mediante cartas, mensajes telefónicos, llamadas telefónicas o emails dirigidos directamente a la persona afectada o a su entorno más próximo, encuentros repetidos no casuales, pintar el auto de la víctima, enviar regalos indeseados, encargar bienes o servicios a nombre de la víctima, allanar su propiedad, efectuar chantaje emocional o falsas acusaciones a través de internet u otros medio de comunicación, formular amenazas $\mathrm{y}$, en alguna ocasión, incluso acometer o asaltar a la víctima?

Como se puede ver, la recurrente del caso en análisis alegó ser víctima de algunos de estos comportamientos -como las llamadas, los mensajes, las vigilancias fuera del domicilio o las difamaciones por internet-, no perdiendo la recurrente la calidad de víctima por el hecho que muchas de las llamadas o mensajes atormentadores hayan sido dirigidas al señor J. O., pues el stalking incluye no solo las llamadas o mensajes directos al afectado sino también a su entorno más próximo.

Desde la arista empírica, un informe de abril del año 1998 efectuado por el Departamento de Justicia de Estados Unidos basado en la encuesta denominada National Violence Against Women (NVAW) Survey, define el stalking como: "a course of conduct directed at a specific person that involves repeated visual or physical proximity, nonconsensual communication, or verbal, written or implied threats, or a combination thereof, that would cause a reasonable person fear" ${ }^{10}$. Dicho informe daba cuenta que una de cada 12 mujeres y uno de cada 45 hombres había sido víctima de stalking en algún momento de sus vidas en Estados Uni$\operatorname{dos}^{11}$. En septiembre de 2012, el mismo Departamento de Justicia estadounidense emitió un informe basado en la encuesta denominada Supplemental Victimization Survey (SVS), arrojando que el porcentaje de mujeres víctimas de stalking seguía siendo mayor que el de

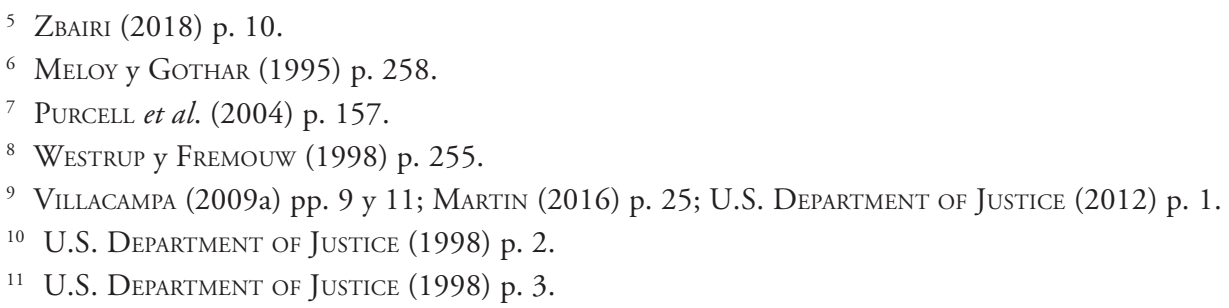


hombres ${ }^{12}$. A su vez se da cuenta que el $70 \%$ de las víctimas conocían a su acosador y que el porcentaje de víctimas es mayor para personas divorciadas o separadas que los casados u otras categorías como relación de simple amistad o vecindad ${ }^{13}$.

Hasta aquí las cosas, no es difícil comprender que el stalking es un comportamiento que requirió ser regulado penalmente en Derecho Comparado. Es en el Estado de California de los Estados Unidos donde se promulga la primera ley anti stalking del mundo que entró en vigor el 1 de enero de 1991 a raíz de la muerte de la actriz Rebeca Schaeffer. ${ }^{14}$ El stalking ha sido penalizado también en otros países como por ejemplo ${ }^{15}$ : el Reino Unido (Inglaterra, Gales, Escocia e Irlanda del Norte $)^{16}$, Alemania $^{17}$, Austria ${ }^{18}$, Italia ${ }^{19}$, Portugal ${ }^{20}$ y España ${ }^{21}$. En el caso español, la reforma al Código Penal introducida por la Ley Orgánica No 1/2015, de 30 de marzo de 2015, incorporó el artículo 172 ter que tipifica penalmente el stalking dentro del capítulo de las coacciones, en el título de los delitos contra la libertad. Destacable mención debe hacerse al preámbulo de esta ley, en el cual se destaca que este nuevo tipo penal de acoso está destinado a ofrecer respuesta a conductas que, en muchas ocasiones, no podían ser calificadas como coacciones o amenazas, al no llegar a producirse necesariamente el anuncio explícito de la intención de causar algún mal o el empleo directo de violencia para coartar la libertad de la víctima ${ }^{22}$.

\section{Ausencia de regulación del stalking en Chile}

En primer lugar, llama la atención la falta de tratamiento de este tema por parte de la doctrina jurídica nacional, mencionándose el stalking solo de forma tangencial y no como tema principal. En textos jurídicos chilenos podemos encontrar a Emanuele Corn, quien habla del agravamiento de la pena que el Código Penal argentino impone a quien matare a una mujer cuando media violencia de género, y advierte que "habría que pensar en lo que en el sistema estadounidense se denomina stalking, o sea, una serie de actos de persecución que en una primera fase no se concretan en violencia física, pudiendo consistir en formas de violencia psicológica, como, por ejemplo, un gran número de llamadas

\footnotetext{
12 U.S. Department of Justice (2012) pp. 1 y 4.

13 U.S. Department of Justice (2012) pp. 1 y 5.

14 Martin (2016) p. 27; Zbairi (2018) p. 28.

15 Se pueden revisar detalles y comentarios de la regulación del stalking en esos países en MARTIN (2016) p. 28-29; y ZBAiri (2018) pp. 28-34.

16 Ver la Ley de Protección contra el acoso del Reino Unido (Protection from Harassment Act 1997) de 1997.

17 Código Penal Alemán (Strafgesetzbuch) de 1871, artículo 238. El delito es denominado Nachstellung, traducible como persecución.

18 Código Penal Austriaco (Strafgesetzbuch) de 1974, artículo 107 a). El delito es denominado Beharrliche Verfolgung, traducible como persecución persistente.

19 Código Penal Italiano (Codice Penale), de 1930, artículo 612 bis. El delito es denominado atti persecutori, traducible como actos de persecución.

20 Código Penal Portugués (Código Penal), de 1982, artículo 154 A). El delito es denominado Perseguição, traducible como persecución.

21 Código Penal Español de 1995, artículo 172 ter.

22 Ley Orgánica No 1/2015 de 2015, punto XXIX del Preámbulo.
} 
telefónicas indeseadas o en horario nocturno, y que solo en ciertos casos evolucionan después en violencias físicas, hasta sus más graves consecuencias" ${ }^{23}$. También se puede citar a Germán Varas Cicarelli quien considera que el quebrantamiento de una orden de alejamiento se puede provocar a través de un comportamiento repetido e intrusivo, específica forma de violencia de género que en otros países se regula bajo la denominación de stalking ${ }^{24}$.

Ahora bien, esta falta de tratamiento del tema en nuestro país podría encontrar una explicación en el subjetivo límite que muchas veces separa una conducta de abuso de una conducta socialmente aceptable, considerada normal o inofensiva, como por ejemplo una llamada telefónica o el envío de un regalo. Basándose en la autora Eugenia Gómez, esta dificultad para distinguir el stalking como una forma de violencia psicológica que merezca ser perseguida como delito ha sido acertadamente mencionada por Carabineros de Chile en un estudio terminado en agosto del año 2017 que levantó los partes generados a nivel nacional por denuncias relativas a amenazas $\mathrm{u}$ otros hechos cuyo contenido refiere a acoso, hostigamiento y otras conductas de índole obsesivas, entre enero de 2016 y agosto de $2017^{25}$. Este informe estratégico -generado por la Dirección de Investigación Criminal (DINCAR) y su Centro de Análisis y Operaciones de Investigación Criminal (CAODI) de Carabineros de Chile- estudió los casos levantados bajo la calificación de lo que en otros países se conoce como stalking, dejando claro que en Chile este tipo de comportamientos no es constitutivo de delito ${ }^{26}$. Las manifestaciones stalking a considerar fueron: las comunicaciones no deseadas como las llamadas o mensajes; la búsqueda de contacto directo como los acercamientos o vigilancias; y las interferencias no deseadas como el pago de una cuenta sin comunicación a la víctima ${ }^{27}$. Entre la clasificación de acosadores, el estudio consideró los siguientes: al acosador rechazado, que mantuvo una relación cercana a la víctima y pretende el regreso o una venganza; el que busca intimidad con la victima creyendo que la persistencia lo hará alcanzar su objetivo; el pretendiente socialmente torpe; el resentido que busca asustar y angustiar a la víctima, probablemente, por problemas interpersonales pasados; y el acosador que derechamente pretende atacar sexualmente a la víctima ${ }^{28}$. Entre los datos obtenidos por este estudio se pueden mencionar los siguientes: las regiones con mayor concentración de casos fueron la Metropolitana $(40,1 \%)$, la $\mathrm{V}^{\mathrm{a}}(11,0 \%)$ y la $\mathrm{VII}^{\mathrm{a}}(9,5 \%)$, mientras que las comunas con mayores registros fueron Santiago $(4,1 \%$,), Puente Alto $(3,2 \%)$ y Rancagua $(2,8 \%)$; del total de 708 casos, el $88,7 \%$ de las víctimas fueron mujeres y el $83,8 \%$ de los hostigadores fueron hombres; el $65,3 \%$ de las veces la relación entre hostigador y víctima era de ex pareja; la mayoría de las víctimas tenía entre 24 y 35 años de edad ${ }^{29}$.

\footnotetext{
23 CoRn (2014) p. 123.

24 VARAS (2012) pp. 160-161.

25 Dirección de Investigación Criminal de Carabineros de Chile (2017) pp. 3 y 13; Gómez (2015) pp. 33-34.

26 Dirección de Investigación Criminal de Carabineros de Chile (2017) p. 3.

27 Dirección de Investigación Criminal de Carabineros de Chile (2017) p. 4.

28 Dirección de Investigación Criminal de Carabineros de Chile (2017) p. 5.

29 Dirección de Investigación Criminal de Carabineros de Chile (2017) p. 12.
} 
Frente a esta falta de regulación del stalking en nuestro país, se debe hacer presente el Anteproyecto de Código Penal que fue presentado al Ministerio de Justicia y de los Derechos Humanos el 17 de octubre de 2018. Este trabajo fue preparado por una comisión mandatada por el referido Ministerio con el fin de sacar un producto final que aprovechara y mejorara los anteproyectos que fueron preparados durante los años 2013 y $2015^{30}$. El texto del aludido Anteproyecto se constituye de dos libros, de los cuales el segundo contiene el Título IV sobre los “delitos contra la intimidad". Dentro de su sección " $\$ 1$. Allanamiento de morada, intromisión en la intimidad, difusión indebida y hostigamiento" se encuentra el artículo 275 que consagra el delito de "hostigamiento" según el siguiente tenor: "Art. 275. Hostigamiento. Será sancionado con libertad restringida o reclusión el que, contra la voluntad expresa de otra persona, afectando con ello gravemente las condiciones de su vida privada, insistentemente: $1^{\circ}$ la siguiere; $2^{\circ}$ intentare establecer contacto con ella; $3^{\circ}$ llamare a su teléfono; $4^{\circ}$ le enviare comunicaciones" 31 .

Sumado a lo anterior, el 14 de marzo de 2019 ingresa a la Cámara Diputados el Mensaje No 393-366 de 8 de marzo de 2019, en virtud del cual el Presidente de la República Sr. Sebastián Piñera inicia un proyecto de ley que sanciona el acoso por cualquier medio. Dicho proyecto sanciona la exhibición y difusión no consentida de material sexual en su artículo $3^{\circ}$, la difusión no consentida de datos personales o de registros de imágenes o sonidos en su artículo $2^{\circ}$, y en lo que a nuestro trabajo concierne, sanciona el acoso en su artículo $1^{\circ}$ del siguiente modo: "Artículo 1.- Acoso. Será sancionado con presidio menor en su grado mínimo a medio el que, contra la voluntad expresa de otra persona, afectando con ello gravemente las condiciones de su vida privada, insistentemente: $1^{\circ}$ la siguiere; $2^{\circ}$ establezca o intentare establecer contacto con ella; $3^{\circ}$ llamare a su teléfono; $4^{\circ}$ le enviare comunicaciones por cualquier medio. Si la víctima fuere menor de dieciocho años, se presumirá que existe voluntad contraria cuando lo señalado en el inciso anterior se realizare por cualquier medio electrónico de comunicación" ${ }^{32}$. Cabe destacar que dentro de sus fundamentos, el proyecto de ley hace expresa mención al stalking como delito regulado en España, Estados Unidos, Reino Unido y Alemania ${ }^{33}$.

No es el objeto de este trabajo analizar los señalados proyectos de ley ni revisar los posibles concursos con otros delitos u otras aristas penales que puedan surgir de esta regulación del stalking, sin embargo, considero positiva esta iniciativa -perfectible o no- por seguir el ejemplo de países desarrollados y regular penalmente este tipo de comportamientos.

Pero hasta que estos proyectos no se concreten en la dictación de una ley, ¿qué herramienta jurídica tiene la víctima de stalking hoy? Como ya expusimos, Germán Varas Cicarelli considera que el stalking puede ser una forma de quebrantar una medida de alejamiento adoptada por violencia intrafamiliar ${ }^{34}$. Aunque es una interesante acotación, no es una

\footnotetext{
${ }^{30}$ Ver carta de 17 de octubre de 2018, de referencia "Entrega de Anteproyecto de Código Penal", dirigida por la Comisión Redactora del Anteproyecto de Código Penal al Ministerio de Justicia y de los Derechos Humanos de Chile, en Comisión Redactora del Anteproyecto de Código Penal 2018 (2018) p. 1.

31 Anteproyecto de Código Penal de 2018, artículo 275.

32 Mensaje No 393-366 de 2019, p. 12.

33 Mensaje No 393-366 de 2019, pp. 6-8.

34 Varas (2012) pp. 160-161.
} 
solución al problema, pues el stalking puede darse fuera del ámbito de la violencia intrafamiliar, ejercido por personas que no cumplen con ninguna de las calidades señaladas en el artículo $5^{\circ}$ de la Ley No 20.066 de 2005. Piénsese por ejemplo cuando es ejercido por la pareja o ex pareja con quien nunca se ha convivido ni se ha estado casado o por un vecino o un desconocido. Por otro lado, más allá que el stalking sea una forma de quebrantar una orden de alejamiento, lo ideal sería que el stalking sea en sí misma la conducta que permita decretar una orden de alejamiento. Sin embargo, pareciera que aún queda una alternativa: el Recurso de Protección de garantías fundamentales. Su informalidad, procedimiento expedito y finalidad cautelar urgente podría ser la solución.

\section{La Corte Redujo todo a los actos de injuria}

En el caso en análisis, al haber rechazado el Recurso de Protección en su totalidad, no acogiendo ninguna de las dos peticiones de la recurrente por estimar que los hechos alegados en sede de protección estaban siendo conocidos en la causa penal de injurias, Rol No 7724-2018 del Juzgado de Garantía de Valdivia, la Corte incurre en un razonamiento simplista y poco acucioso de los actos invocados como atentatorios de derechos fundamentales. La Corte reduce los hechos alegados por la recurrente únicamente a los hechos constitutivos del delito de injuria que afectan la honra, desatendiendo completamente los actos de stalking y la segunda petición relativa a ordenar que dichos actos se detengan.

No obstante, este error de la Corte encontraría su raíz en la deficiente estructura argumental planteada por la recurrente en su recurso. Si bien de su relato es posible identificar actos constitutivos de injurias con publicidad, por un lado, y actos constitutivos de stalking, por otro, culminando por efectuarse dos peticiones distintas a la Corte, esta distinción se desploma cuando la recurrente invoca como derecho fundamental afectado únicamente la honra. Esta invocación guarda coherencia argumental respecto a las publicaciones agraviantes a través de internet y la primera petición a la Corte consistente en que ordene a la recurrida borrar dichas publicaciones, pero no es un derecho que guarde coherencia argumental con los actos constitutivos de stalking y la segunda petición a la Corte de ordenar que la recurrida cese todo otro acto de acoso. Respecto a estos últimos actos habría resultado más adecuado que la recurrente invocara como vulnerados los derechos fundamentales que se expondrán en el capítulo que continúa.

\section{DERECHOS FUNDAMENTALES AFECTADOS POR EL STALKING}

Al haber invocado solo la honra como derecho fundamental agraviado, la recurrente indujo a la Corte a fijarse solo en los actos constitutivos de injuria con publicidad cuya eliminación la recurrente solicita como primera petición, diluyendo en estas injurias los actos constitutivos de stalking cuya abstención la recurrente solicitó como segunda petición. Por lo anterior, en este acápite procederé a tratar tanto el derecho a la integridad psíquica como el derecho a la vida privada, garantías fundamentales cuya afectación la recurrente debería haber alegado a propósito de los actos de stalking, sin perjuicio de alegar también la afectación de su derecho a la honra producto de los actos de injuria. Pero además de los dos derechos fundamentales antes señalados, indicaré cómo los actos de stalking afectan la 
libertad de autodeterminación o de obrar, la cual podría considerarse -sin ser una opinión asentada- una forma del derecho a la libertad personal consagrada en el No 7 del artículo $19^{\circ}$ de la CPR.

\section{Derecho a la integridad pSÍQuica (ART. 19 No 1 CPR)}

La victima de stalking ve afectado, en primer lugar, su derecho a la integridad psíquica consagrado en el numeral $1^{\circ}$ del artículo $19^{\circ}$ de la CPR. Como primer argumento, debemos volver sobre la idea que el miedo y la angustia son consecuencias propias del stalking, un verdadero quiebre de la vida cotidiana que sufre la víctima. Lo anterior permite sostener que basta el Principio de Normalidad para tener por acreditada la afectación del derecho a la integridad psíquica ${ }^{35}$.

En Derecho Comparado, Royakkers conceptualiza el stalking precisamente como " $a$ form of mental assault" ${ }^{36}$. En la misma línea, se ha opinado que el stalking afecta no solo la libertad de la víctima sino también su tranquilidad y salud mental ${ }^{37}$. En consideración a lo anterior, la mayoría de la doctrina ha descartado la integridad moral como bien jurídico protegido por el delito de stalking, desde que este tipo delictivo no tiene por qué suponer necesariamente un trato denigrante, no constituyendo necesariamente un supuesto de acoso moral pero sí psicológico que produce un desequilibrio emocional ${ }^{38}$.

En el ámbito nacional, la protección de la integridad psíquica también puede apoyarse en los fallos que han acogido Recursos de Protección interpuestos por vulneración a la integridad psíquica producida por llamados de cobranza efectuados en forma abusiva e insistente. Estos fallos guardan interesantes características: se declaró que las llamadas telefónicas reiteradas constituían ejercicio abusivo e irracional de una facultad, afectándose la integridad psíquica del recurrente, acogiéndose el recurso y ordenándose a la empresa de cobranza recurrida que se abstenga de seguir efectuando llamadas telefónicas al recurrente $^{39}$. A pesar de tratarse de jurisprudencia relativa a materia de cobranza en contexto de Derecho del Consumidor, es jurisprudencia útil en relación al stalking. De partida demuestran cómo las víctimas de un determinado comportamiento nocivo que no tiene regulación penal, buscan tutela a través del Recurso de Protección. En segundo lugar, se

\footnotetext{
35 El Principio de Normalidad es frecuentemente utilizado para tener por establecido el daño moral en consideración a determinadas circunstancias de las cuales este tipo de perjuicios fluye por la naturaleza de las cosas. Así, por ejemplo, la Corte Suprema ha explicado "que si bien es cierto que la indemnización debe ser concedida solamente en favor de aquéllas que acrediten haber sufrido real y efectivamente el daño, tratándose del daño moral -y muy particularmente en la situación que se revisa- no puede ser omitido un principio probatorio elemental en materia civil, cual es el denominado principio de la normalidad, según el cual quien alega lo normal, lo habitual, lo común u ordinario, no tiene el peso de la prueba, el que recae sobre la parte que postula lo anormal, excepcional o extraordinario.", en VALLS Y OTROS CON RED DE TELEVISIÓN CHILEVISIÓN S.A. (2019) considerando $4^{\circ}$.

36 RoYyakers (2000) p. 7.

37 Maugeri, (2016) p. 227; Martin (2016) p. 25; Zbairi (2018) p. 13.

38 Zbairi (2018) p. 14; Lora (2017) p. 22.

39 Ver Karstegl con Banco Falabella (2018); Olivares con Ripley ChILE S.A. (2017); Muñoz CON EMPRESA NACional de TELECOMUnicaciones S.A. (2017); Hassen con SerVICIOS Y Administración de CRÉditos Comerciales PRESTO S.A. (2016).
} 
ve cómo las Cortes han brindado la protección solicitada, ordenando la abstención del hostigamiento. Por otro lado, aunque la jurisprudencia citada es limitada solo a una forma de stalking -las llamadas telefónicas-, cabe tener presente que si la Corte es capaz de acoger Recursos de Protección cuando es una empresa de cobranza la que afecta la integridad psíquica ¿por qué no podría hacerlo cuando el hostigador es una persona natural? Si se ha ordenando detener las llamadas ¿por qué no podría ordenarse que se detengan los mensajes, los regalos indeseados o las vigilancias fuera del hogar? Es más, si las Cortes de Apelaciones han ordenando cesar actos de hostigamiento provenientes de empresas de cobranza por vulnerar la integridad psíquica, con mayor razón deberían hacerlo cuando los hostigamientos provienen de una ex pareja o incluso un personaje anónimo que se oculta para producir temor, un quiebre de vida, una distorsión de la autonomía personal que obliga a la víctima a adoptar decisiones - como cerrar redes sociales o cambiarse de trabajo- para evitar al acosador.

\section{Derecho a la Vida Privada (ARt. 19 No 4 CPR)}

El numeral $4^{\circ}$ del artículo $19^{\circ}$ de la CPR asegura a toda persona y su familia el respeto y protección de la vida privada y la honra, como además, la protección de sus datos personales. Si consideramos que la víctima de stalking se ve reiteradamente rondada e invadida por contacto no deseado de parte de un tercero, ¿podríamos decir que ve afectada su privacidad?

Revisando lo que la doctrina constitucional tradicional entiende por vida privada, encontramos por ejemplo a Cea Egaña para quien la vida privada se constituye por el "conjunto de los asuntos, conductas, documentos, comunicaciones, imágenes o recintos que, el titular del bien jurídico protegido, no desea que sean conocidos por terceros sin su consentimiento previo" ${ }^{40}$. Para Novoa Monreal la vida privada tiene cuatro componentes característicos: un elemento objetivo que se manifiesta con la intromisión en la intimidad de otro tomando conocimiento de aspectos que se querían mantener reservados, no siendo necesaria divulgación; un elemento subjetivo consiste en el deseo de que ciertos hechos no sean conocidos por terceros; un bien jurídico protegido que es el recato o pudor; y finalmente la irrelevancia de la verdad o falsedad de los aspectos íntimos que la persona desea ocultar $^{41}$. Por su parte, nuestro Tribunal Constitucional -siguiendo a Hernán Corral y a Ángela Vivanco- ha planteado que el derecho a la privacidad es la posición en la que un sujeto se encuentra libre de intromisiones o difusiones cognoscitivas de hechos que pertenecen a su interioridad corporal y psicológica o a las relaciones que ella mantiene o ha mantenido con otros ${ }^{42}$.

Con más especificidad conceptual, Ángela Vivanco considera la privacidad como el bien jurídico protegido, distinguiendo la noción de vida privada de la de intimidad. La vida privada consistiría en la reserva frente a terceros de ciertos hechos o actos, pero pu-

40 CeA (2012) Tomo II, p. 199.

41 Novoa (1989) pp. 58, 59, 77 y 81.

42 ReQuerimiento de inconstituCionalidad a modificaCiones al Código del Trabajo, boletín No 9835-13, Rol No 3016-16, considerando $6^{\circ}$, pp. 153-154. 
diendo dicha reserva ser levantada si hay consentimiento, interés público o exigencias de publicidad que hace el propio Ordenamiento Jurídico. La intimidad, en cambio, abarca aspectos tan personales que quedan sustraídos del conocimiento público o intervención de los demás por un asunto de dignidad, no pudiendo aceptarse en ningún caso una pretensión de interés público, como por ejemplo el acto sexual ${ }^{43}$.

En cuanto a la delimitación entre el ámbito privado y el público, tradicionalmente se sostiene que lo relevante para determinar la protección a la privacidad es el lugar, no siendo protegible lo que ocurre en un lugar público. Pero también se ha sostenido que el criterio está en la naturaleza privada de la conducta o comunicación, por lo que trasgrede la privacidad el fotografiar a una persona o grabar sus conversaciones aunque ello suceda en un lugar público ${ }^{44}$.

Hasta acá lo expuesto resulta difícil relacionar stalking y vida privada desde que más allá de las diferencias que puedan haber entre las nociones de vida privada, privacidad e intimidad, y más allá de la protección de la privacidad en un ámbito público o privado, se repite un mínimo común denominador consistente en la intromisión en la intimidad de otro tomando conocimiento de aspectos que se querían mantener reservados. ${ }^{45} \mathrm{El}$ problema es que esto no es algo propio del stalking, fenómeno que para producirse no necesita que el acosador obtenga o pretenda obtener información de la víctima.

No obstante lo anterior, sí es posible encontrar doctrina que avanza sobre esta visión tradicional ${ }^{46}$. Mario Verdugo, Emilio Pfeffer y Humberto Nogueira explican que la vida privada e intimidad es "el derecho a poder estar solo si uno lo desea, a mantenerse apartado de las observaciones de los demás sin ser molestado, sin intromisiones en lo más personal de su vida, es en cierta forma una emanación de la libertad personal” ${ }^{37}$. Por otro lado, para Evans de la Cuadra el concepto de vida privada está directamente vinculado al de intimidad, ámbito humano de convivencia, superación, planificación y progreso, sin la intervención o presencia de terceros ${ }^{48}$. También se ha sostenido que el derecho al respeto y protección de la vida privada tiene que ver con la "esfera o zona de acción humana que, provista de protección constitucional, impide la interferencia de terceros a la esfera íntima de la persona, a los datos que la protegen y, a la vez, permite la autonomía individual y el autodesarrollo de la personalidad" 49 . En cuarto lugar, podemos tomar las ideas de Ruth Gavison, quien considera que son tres los elementos que componen la estructura del concepto de intimidad, teniendo en común la noción de accesibilidad a la vida privada, pero con

43 VIVANCO (2006) Tomo II, pp. 348-349.

44 Vivanco (2006) Tomo II, p. 347.

45 Esta misma idea de acceso o captación de aspectos personales es la plasmada en las normas que sancionan penalmente atentados a la privacidad. Véase artículo 36 B leras c) y d) de la LeY No 18.168 de 1982; artículos 161 A y 161 B del Código Penal de 1874; y Ley No 19.223 de 1993.

46 Rodolfo Figueroa ha destacado que en Chile existe una extensa pero poco sistematizada literatura referida a la privacidad y que una visión más compleja permitiría exceder la mera distinción entre captación y divulgación de información, pudiendo apreciarse mejor las diferentes formas en que se puede dañar el derecho a la privacidad, en Figueroa (2013) pp. 883-884

47 Verdugo et al. (2005) p. 250.

48 Evans de la Cuadra (1999) Tomo I, p. 213.

49 García y Contreras (2014) p. 326. 
afectaciones independientes entre sí: el primer elemento se constituye por el secreto, que dice relación con la cantidad de información que se tiene sobre un individuo; el segundo se constituye por el anonimato, relacionado con la atención que se presta a una persona que pierde intimidad cuando es observada de manera no querida; y el tercero se constituye por la soledad, consistente en impedir el acceso real y directo a un individuo ${ }^{50}$. Además, destacable resulta el trabajo de Rodolfo Figueroa, quien analiza las dimensiones de la privacidad que propone Daniel Solove. La cuarta dimensión, denominada “invasión”, guarda la distintiva característica de no requerir necesariamente la captación de información ${ }^{51}$. Esta dimensión tiene dos manifestaciones: la primera, denominada "interferencia decisional", consiste en la interferencia efectuada sobre las decisiones personales relativas a determinadas materias de vida; la segunda, denominada "intrusión”, consiste en entrometerse en la soledad, en la reclusión de un individuo, en su tranquilidad ${ }^{52}$. Finalmente, García y Contreras también han entendido que dentro de las finalidades que busca la protección de la vida privada se encuentran no solo la limitación de la exposición y conocimiento de aspectos personales por parte terceros, sino que también la limitación del contacto físico y la promoción de la autorrealización personal sin presiones ni interferencias indeseadas ${ }^{53}$.

En síntesis, de todos estos autores emerge una arista de la privacidad que no tiene que ver con la captación de información, sino que consiste en el simple derecho a vivir la vida, desarrollar la personalidad y tomar decisiones en forma autónoma y tranquila, sin injerencia de terceros indeseados, un derecho a la soledad, que es precisamente lo que el stalking quebranta.

Cabe mencionar que la idea del derecho a la privacidad como uno de los derechos fundamentales afectados por el stalking, no es una novedad de este trabajo. Por ejemplo, el autor Baucells i Lladós no considera tan nítido entender que la libertad es el único bien jurídico protegido por el delito de stalking, analizando también la intimidad. ${ }^{54}$ Por su parte, Royakkers diferencia seis componentes del stalking, consistiendo el cuarto de ellos en la irrupción en el mundo privado de la víctima, que en sus palabras explica del siguiente modo: "breaking into the life-world of another indicates that the perpetrator is violating the personal life sphere of the victim, i.e. the most intimate part of his/her life. The life-world is defined as the physical, mental, and emotional space that everybody needs to be and develop as a person" ". Carolina Villacampa opina que el elemento más característico de la definición de Royakkers es la "vulneración de la vida privada de la víctima"56. Anna María Maugeri también sostiene que el stalking implica la invasión de la esfera privada de la víctima, alterando

50 Gavison (1980) pp. 428-436.

51 Figueroa (2013) p. 879, basándose en Solove (2009) p. 161.

52 Figueroa (2013) p. 879, basándose tanto en Solove (2009) pp. 162 y 166 como en Warren y BrandeIS (1890) pp. 193-220.

53 García y Contreras (2014) p. 327, basándose en Martínez de Pisón (1993) pp. 75 y ss.

54 Baucells i Lladós (2014) pp. 80-82.

55 ROYYAKERS (2000) p. 7.

56 Villacampa (2009a) p. 11. 
su tranquilidad ${ }^{57}$. En la misma línea se puede mencionar la consideración del stalking como una forma de violentar la distancia que media entre las relaciones humanas ${ }^{58}$.

Como último argumento para considerar la privacidad como un derecho violentado por el stalking, se debe tener presente que tanto el anteproyecto de Código Penal como el proyecto de ley a los que se aludió en el segundo capítulo de este trabajo regulan el stalking como un delito contra la vida privada e intimidad.

Para cerrar, cabe mencionar que al ser los derechos a la intimidad y a la honra derechos personalísimos, la afectación de estos atributos inalienables acarrea normalmente una afectación psíquica, por lo que existe una relación con el derecho del numeral $1^{\circ}$ inciso primero del artículo $19^{\circ}$ de la CPR ${ }^{59}$.

\section{Derecho a la Libertad de Autodeterminación como forma de la Libertad Personal (Art. 19 No 7 CPR)}

Finalmente, se debe tener presente que el stalking afecta la libertad de la víctima desde una arista particular. Pensemos en una persona que para escapar de su hostigador se ve forzada a cerrar una red social, a cambiarse de barrio o de trabajo o a tomar un camino alternativo para llegar algún lugar. En todas estas circunstancias nos encontramos frente a una persona cuya libertad para decidir y desenvolver su vida se ha visto restringida. En razón de lo anterior, en España la mayoría de la doctrina considera la libertad de obrar como el bien jurídico afectado por la angustia y el temor que produce el stalking. Esta libertad entendida en sentido amplio abarca tres fases del proceso volitivo: libertad de formación, de decisión y de ejecución de la voluntad ${ }^{60}$. Así, se ha sostenido que hay conductas que afectan la libertad de ejecución junto a la de decisión si se piensa, por ejemplo, en "las conductas de vigilancia o perseguir, las cuales pueden afectar a la toma de una decisión la cual desencadena en la realización de una conducta distinta a la que se hubiese adoptado de no haber existido dicha conducta de acoso"61. En la misma línea, se ha argumentado que el stalking altera el proceso de adopción y ejecución de decisiones, lo cual atenta contra la libertad aunque con características especiales, de modo que el delito de stalking se encuentra correctamente ubicado en el Código Penal español en el título de los delitos contra la libertad, pero debería tener un capítulo aparte y no en las coacciones ${ }^{62}$.

\footnotetext{
7 Maugeri (2016) p. 227.

58 Villacampa (2009b) p. 54; Zbairi (2018) p. 14.

9 CEA (2012) Tomo II, p. 193.

60 Martínez (2018) p. 11; y Lora (2017) p. 22. Cabe mencionar que es debatido en doctrina sobre si el delito de stalking busca proteger solo una de las tres fases del proceso volitivo de la libertad de obrar o si el buen jurídico protegido es la seguridad individual o la integridad moral. Para revisar con más detalle esta discusión puede verse MARTínez (2018) pp. 10-15; LORA (2017) pp. 21-23 y 52; y TAPIA (2016) pp. 134-143.

61 Lora (2017) p. 23.

${ }^{62}$ Gutiérrez (2013) pp. 583-584; Tapia (2016) p. 135; Roig (2018) p. 328.
} 
A mayor abundamiento, cabe destacar que no solo el Código Penal español regula el stalking dentro de los delitos contra la libertad, sino que así ocurre igualmente en Alemania, Austria, Italia y Portugal ${ }^{63}$.

En Chile, la libertad de autodeterminación ha sido puesta de relieve por la doctrina penal. Así, en un estudio sobre las amenazas y las coacciones, Francisco Maldonado ha explicado que si el resultado delictivo consiste en que el individuo deja de hacer algo que desea o hace algo que no quiere, su capacidad de decidir se reduce o se encuentra impedido de obrar, reduciéndose sus competencias para actuar y motivarse, viéndose comprometida su libertad de autodeterminación ${ }^{64}$.

Ahora pasando al plano constitucional, ¿sería posible considerar que la libertad personal a la que se refiere el numeral $7^{\circ}$ del artículo $19^{\circ}$ de la CPR engloba a la libertad de autodeterminación? Existe apoyo para decir que sí. En primer lugar y continuando en el ámbito penal, Antonio Bascunán ha señalado que el bien jurídico protegido en las amenazas condicionales y coacciones violentas es el mismo: "la libertad personal entendida como libertad de acción, es decir como ausencia de obstáculos ilegítimos al desenvolvimiento de la propia capacidad de actuación en el marco de la vida social" ${ }^{5}$. Luego, revisando lo que se entiende por libertad personal en materia constitucional, García Morillo indica que es el derecho "de disponer de la propia persona y de determinar la propia voluntad y actuar de acuerdo con ella, sin que nadie pueda impedirlo, siempre que no exista una prohibición constitucionalmente legítima" ${ }^{36}$. El autor explica que no debe confundirse la libertad personal con la libertad de residencia y la de circulación, debiendo concebirse estas últimas de acuerdo con una relación externa mientras que la libertad personal es relativa a la persona en sí considerada, por lo que las libertades de residencia y circulación pueden verse limitadas sin que se deje de gozar de plena libertad personal ${ }^{67}$. En Chile, alguna doctrina ${ }^{68} y$ jurisprudencia constitucional ${ }^{69}$ se ha servido de la distinción de García Morillo para entender que el numeral $7^{\circ}$ del artículo $19^{\circ}$ de nuestra CPR contiene una consagración amplia de libertad personal, siendo la libertad ambulatoria y de residencia una consecuencia de la misma, tal como lo expresa la frase ubicada entre el encabezado y la letra a) de la norma

${ }_{63}$ En el Código Penal Español de 1995, el artículo 172 ter se enmarca dentro del "Título VI Delitos contra la libertad"; en el Código Penal Alemán (STRafgesetzbuch) de 1871, el artículo 238 se enmarca dentro del "Achtzehnter Abschnitt Straftaten gegen die persönliche Freiheit"; en el Código Penal Austriaco (STRAFGesetzBUCH) de 1974, el artículo 107 a) se enmarca dentro del "Dritter Abschnitt Strafbare Handlungen gegen die Freiheit"; en el Código Penal Italiano (Codice Penale) de 1930, el artículo 612 bis se enmarca dentro del "Capo iII Dei delitti contro la liberta individuale"; y en el Código Penal Portugués (Código Penal) de 1982, el artículo 154 A se enmarca dentro del "Capitulo IV Dos Crimes contra a liberdade pessoal".

${ }^{64}$ Maldonado (2018) pp. 15 y 37.

65 BASCUÑÁn (1994) p. 282.

${ }^{66}$ García (1995), p. 42.

67 García (1995), p. 35.

${ }^{68}$ García y Contreras (2014) pp. 296, 297 y 609.

69 Así por ejemplo ha argumentado Marisol Peña, Francisco Fernández, Carlos Carmona y Gonzalo García en las consideraciones para rechazar el requerimiento de inaplicabilidad, en REQUERIMIENTO DE INAPLICABILIDAD POR INCONSTITUCIONALIDAD RESPECTO DEL INCISO FINAL DEL ARTICULO 40 DE LA LEY No 18.287, Rol No 1804-10, considerando $11^{\circ}-14^{\circ}$, pp. $17-18$. 
señalada. En esta misma línea, para Humberto Nogueira la libertad personal consagrada en el encabezado del artículo 19 No 7 de la CPR es un derecho genérico como libertad de la persona física en cuanto ser corporal: "es el derecho de toda persona a que los poderes públicos y terceros no interfieran en la esfera de autonomía personal, vale decir, de disponer de su propia persona y de actuar determinado por la propia voluntad sin otras limitaciones que las que imponen el medio natural, los derechos de los demás y el ordenamiento constitucional"70. A mayor abundamiento, la distinción entre libertad personal y libertad de circulación y de residencia se puede apoyar en el tratamiento normativo diferenciado que hace tanto el Pacto Internacional de Derechos Civiles y Políticos (artículos $9^{\circ}$ y $12^{\circ}$ ) como la Convención Americana sobre Derechos Humanos (artículos $7^{\circ}$ y 22$)^{71}$. Por tanto, se debe tener presente la idea amplia de libertad como la "facultad para autodeterminarse" 72 . En similar sentido, Evans de la Cuadra explica que la esencia de la libertad de una persona consiste en "el derecho a desarrollar su vida en la comunidad en que nació y donde está viviendo"73. Por lo demás, ya en la historia fidedigna de nuestra CPR se podía encontrar una noción de libertad personal como libertad de obrar en sentido distinto a la libertad de desplazamiento. Así, Silva Bascuñán distinguió tres conceptos de libertad personal: en primer lugar, la libertad individual de una persona para obrar libremente en busca del pleno desarrollo de su personalidad, sin actuar contra la ley y en perjuicio de terceros; en segundo lugar la libertad de locomoción dentro del territorio de la República; y finalmente la seguridad individual en cuanto a no ser objeto de detención o privación de la libertad que impida desarrollar la personalidad ${ }^{74}$.

No obstante, todo lo anteriormente expuesto, existen opiniones que alejan la libertad de obrar de la libertad personal consagrada en el numeral $7^{\circ}$ del artículo $19^{\circ}$ de la CPR. En primer lugar, se ha estimado que dicha norma contiene un concepto restrictivo de libertad personal, alusivo únicamente a la libertad de desplazamiento y de residencia ${ }^{75}$. En segundo lugar, asimilando la libertad de autodeterminación con el libre desarrollo de la personalidad entendido como "el derecho de toda persona a actuar lícitamente sin sufrir interferencias arbitrarias" ${ }^{76}$, se ha sostenido que este derecho no es lo mismo que la libertad personal, encontrándose más bien en la frontera de los numerales $4^{\circ}$ y $7^{\circ}$ del artículo $19^{\circ}$, es decir, entre las libertades innominadas bajo las expresiones "vida privada" y "libertad personal”. De este modo, la libertad para desarrollar la personalidad quedaría -junto con la libertad de casarse y la libertad sexual- comprendida dentro de la libre elección de la vida

\footnotetext{
70 Nogueira (2002) p. 162.

71 Nogueira (2002) p. 162; García y Contreras (2014) p. 297.

72 Verdugo et al. (2005) p. 234. Por su parte, la Corte Interamericana de Derechos Humanos ha señalado que la libertad en sentido amplio es "el derecho de toda persona de organizar, con arreglo a la ley, su vida individual y social conforme a sus propias opciones y convicciones", en CHAPARRO ÁLVAREZ Y LAPO ÍNIGUEZ. VS. ECUADOR (2007) párrafo 52.

73 Evans de la Cuadra (1999) Tomo II, p. 202.

74 Comisión Constituyente (1975) sesión 106a , p. 5.

75 Bronfman et al. (2012) p. 486; CEA (2012) Tomo II, p. 257; ACCIÓN DE INAPLICABILIDAD POR INCONSTITUCIO-

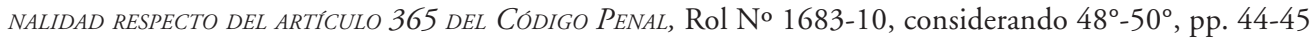

76 García y Contreras (2014) p. 630.
} 
privada contemplada en el artículo 19 No 4 de la CPR 77 . En una línea similar, se ha señalado que la libertad del individuo para gobernar su propia vida en forma autónoma se encontraría amparada en los numerales $4^{\circ}$ y $5^{\circ}$ del artículo $19^{\circ}$ de la $\mathrm{CPR}^{78}$.

En conclusión, si bien existe apoyo para sostener que el encabezado del numeral $7^{\circ}$ del artículo $19^{\circ}$ de la CPR consagra una noción amplia de libertad personal que abarca la libertad para obrar en la vida en base a decisiones autónomas y libres de temores e injerencias ilegitimas de terceros como lo son las amenazas, las coacciones o los actos de stalking, esta no es una postura asentada. En segundo lugar, el derecho a la libertad personal y seguridad individual no figura dentro del catálogo de derechos protegidos por el Recurso de Protección en el artículo $20^{\circ}$ de la CPR, encontrando tutela especial a través del Recurso de Amparo. Sin perjuicio de los dos alcances anteriores, es necesario tener presente el tema desde que la libertad de autodeterminación ha sido el bien jurídico protegido al ser tipificado penalmente el stalking en Derecho Comparado.

\section{LA ERRÓNEA CONSIDERACIÓN DE LA CAUSA PENAL POR INJURIAS PARA RECHAZAR EL RECURSO}

1. El bien JURídico PROTEGIDO EN LA CAUSA PENAL POR INJURIAS NO ERA LA HONRA DE LA RECURRENTE

La Corte consideró que los hechos fundantes del recurso estaban sometidos al conocimiento de un tribunal competente, haciendo referencia al Juzgado de Garantía de Valdivia que estaba conociendo la causa Rol No 7724-2018. La Corte expresa que sería dicho tribunal el que tiene la competencia para establecer la existencia o no de los hechos que motivaron el Recurso de Protección y las responsabilidades pertinentes. Así las cosas, se entiende que la Corte rechaza el recurso por considerar innecesario proteger el derecho fundamental a la honra de la recurrente por los hechos esgrimidos en consideración a que dicho derecho a la honra ya estaría siendo protegido de esos mismos hechos bajo la forma de bien jurídico protegido del delito de injurias en un proceso penal. El conocimiento de los hechos por parte del juez de garantía despojaría al Recurso de Protección de la característica de necesidad de tutela cautelar urgente de su derecho fundamental a la honra. El problema es que dicho razonamiento tendría sentido si la causa Rol No 7724-2018 hubiese sido incoada por la recurrente. Sin embargo, la situación es inversa: la causa penal fue iniciada por querella presentada el 10 de diciembre de 2018 por la recurrida contra la recurrente por el delito de injurias graves hechas por escrito y con publicidad.

En suma, en la causa penal es la recurrida quien imputa actos injuriosos a la recurrente, ocurriendo lo inverso en la causa de protección, por lo que resulta improcedente que la Corte haya dejado sin tutela de su derecho a la honra a la recurrente en razón de un proceso penal en curso donde es el derecho a la honra de otra persona el que se estaría viendo afectado, sin perjuicio de girar todo en base al mismo contexto.

77 García y Contreras (2014) pp. 326, 328, 631 y 632.

78 Bronfman et al. (2012) p. 129. 


\section{La Corte debió encargarse de la SEgunda Petición de ordenar QUe Se DETENGAN LOS ACTOS DE ACOSO ${ }^{79}$}

Pareciera que toda la responsabilidad ha recaído en la recurrente quien debería haber precisado que, además de verse afectada su honra por las publicaciones agraviantes que pide sean borradas, se ve afectada su integridad psíquica y su vida privada por los demás actos de acoso cuyo cese también solicita. No me parece que esta sea una excusa para que la Corte haya hecho un análisis reduccionista de los hechos y peticiones de la recurrente, por dos razones.

En primer lugar, recuérdese que el Recurso de Protección es un recurso informal, sencillo, sumarísimo, de tutela urgente de derechos fundamentales, que ni siquiera requiere el patrocinio de un abogado para ser interpuesto. Por lo anterior, no es extraño que en la práctica la Corte se encuentre ante hechos evidentemente atentatorios de determinados derechos fundamentales cuya afectación no se invocó expresamente. Al respecto acogemos las palabras textuales de Humberto Nogueira: "La sentencia de protección debe respetar la congruencia procesal, ateniéndose por regla general, a lo alegado y probado en el proceso. Sin perjuicio de ello, el tribunal que conoce de la acción de protección tiene la posibilidad de examinar de oficio la existencia de un derecho constitucional cuya afectación no ha sido alegada, lo que debe ser puesto en conocimiento del recurrido y en caso de que éste se encuentre efectivamente afectado, acordar el restablecimiento inmediato del ejercicio del mismo" ${ }^{80}$. Esto es precisamente lo que la Corte de Valdivia pudo haber hecho con el derecho a la integridad síquica y a la privacidad en el caso analizado, a pesar de no haber sido alegados.

En segundo lugar, la Corte ha incurrido en un supuesto de incongruencia procesal, la que puede entenderse como la falta de adecuación entre las pretensiones de las partes y la parte dispositiva de la resolución judicial, y para determinarla corresponde comparar lo reclamado por los litigantes con lo resuelto ${ }^{81}$. Siguiendo a Jaime Guasp y Pedro Aragoneses, la incongruencia procesal tiene tres manifestaciones: la positiva cuando el juez da o rechaza más de lo que se reclama; la negativa cuando el juez omite decidir sobre alguna de las pretensiones procesales tanto cualitativa como cuantitativamente; y mixta cuando la sentencia reúne los dos vicios anteriores, concediendo algo distinto de lo pedido por las partes ${ }^{82}$. Por su parte, nuestra Corte Suprema explica que la incongruencia puede ser ultra petita cuando se otorga más de lo solicitado; extra petita cuando el juez extiende el pronunciamiento a cuestiones no sometidas a su decisión; infra petita cuando el juez decide sobre una pretensión en extensión menor que lo solicitado; o citra petita cuando el juez omite pronunciarse sobre algo que fue introducido en el debate ${ }^{83}$. En el fallo analizado, la Corte ha incurrido en una clara incongruencia negativa o citra petita desde que, con independencia del de-

\footnotetext{
79 En circunstancias que con la primera crítica la justificación del rechazo del recurso de protección cae por sí sola, la crítica que a continuación se expondrá partirá de la hipótesis que efectivamente hubiese sido la recurrente quien se querelló por injurias contra la recurrida.

80 Nogueira (2007) p. 119. La misma idea en Nogueira (2010) p. 271.

81 Comercial Lama Limitada con SerViCio de Impuestos Internos VIII DR CONCEPCIÓN (2019) considerando $3^{\circ}$.

82 Guasp y Aragoneses (2005) pp. 541-542.

83 Constructora el Medano Limitada contra Municipalidad de Santiago (2018) considerando Cuarto.
} 
recho fundamental invocado, de la propia redacción del fallo se desprende que la Corte tenía claro que las peticiones eran dos: "se ordene a la recurrida eliminar las publicaciones y comentarios de Facebook a la vez que se abstenga de realizar cualquier acción de acoso, injuria o burla y de entorpecer su relación sentimental, con costas" ${ }^{84}$. Por tanto, bajo el razonamiento efectuado por la Corte podría comprenderse el rechazo a la primera petición relativa a borrar las publicaciones de Facebook, pues ello tiene que ver con actos injuriosos contra la honra que eran materia de un proceso penal en curso al momento del Recurso de Protección, pero ¿̇de qué manera este proceso penal podía detener y sancionar los otros actos de acoso como las llamadas, los mensajes y el merodeo del domicilio? Sencillamente la segunda petición quedó a la deriva, sin que el proceso penal por injurias justifique que la Corte haya incurrido en esta omisión de pronunciamiento, dejando al recurrente sin protección frente a los actos de stalking, y trasgrediendo un principio básico del Derecho Procesal cual es la congruencia.

\section{COMENTARIOS FINALES}

En este trabajo hemos revisado un caso cuyas aristas fácticas merecen especial atención al guardar coincidencia con determinados comportamientos constitutivos de lo que se ha denominado stalking. Este fenómeno presenta un flanco jurídico abierto en nuestro Ordenamiento Jurídico, por lo que resultan loables las recientes iniciativas legales por tipificar el stalking como un delito, siguiendo el ejemplo del Derecho Comparado. Sin embargo, las víctimas necesitan una herramienta hoy. Dicha herramienta de tutela urgente de la que se pueden servir actualmente los ciudadanos es el Recurso de Protección, siendo posible argumentar que el stalking afecta tanto el derecho fundamental a la integridad psíquica como el derecho a la vida privada. Adicionalmente, se debe tener presente que muchas veces la víctima modifica sus decisiones de vida para escapar de su acosador, viéndose afectada su libertad de autodeterminación o de obrar.

En la causa Rol No 2261-2018, la Corte de Apelaciones de Valdivia se vio enfrentada a un recurso por dos tipos de actos y dos peticiones concretas: unos actos constitutivos de injuria con publicidad, solicitándose que se ordene la eliminación de las publicaciones injuriosas, y otros actos constitutivos de stalking, solicitándose que se ordene el cese de dichos actos de acoso. Sin embargo, ni la recurrente ni la Corte de Apelaciones lograron abordar este conflicto jurídico como correspondía. La recurrente diluyó los actos de stalking en los actos injuriosos al haber invocado como afectado únicamente su derecho a la honra en lugar de diferenciar señalando que las publicaciones injuriosas afectaban su honra y los actos de acoso afectaban su integridad psíquica y su vida privada. Dicho reduccionismo llevó a la Corte a poner su foco de atención solo en las publicaciones injuriosas, lo que termina por llevarla a rechazar el Recurso de Protección en su totalidad en razón de existir una causa penal pendiente por injurias. La forma de resolver de la Corte no fue la adecuada pues, si los hechos hubieran ocurrido, debió haber acogido el Recurso de Protección al menos parcialmente. En este sentido, y siguiendo la teoría que permite a las Cortes

84 L. CON E. (2019) considerando $1^{\circ}$. 
proteger de oficio derechos fundamentales no expresamente señalados por el recurrente si de los hechos es posible desprender su afectación, la Corte debió haberse hecho cargo de la segunda petición de la recurrente y ordenar el cese de todo acto de acoso. En segundo lugar, al no tener que ver la segunda petición con actos de injuria sino con actos de stalking, la causa penal por injurias a la que se remitió la Corte no justifica el haber omitido pronunciamiento sobre la segunda petición, incurriendo en una incongruencia negativa o citra petita.

Lo sucedido en este caso no sorprende. En nuestro país el stalking no ha recibido la merecida atención desde el punto de vista jurídico. Así las cosas, no resulta extraño encontrar una falta de capacidad de parte tanto de los abogados como de los jueces para poder distinguir el stalking con contornos propios y reaccionar adecuadamente frente a él. Es de esperar que este trabajo sirva como una alerta para que las Cortes de Apelaciones pongan más atención al enfrentarse a este tipo de casos y comprendan que, mientras el stalking no se tipifique penalmente, el Recurso de Protección puede ser la única esperanza de tutela urgente con la que pueden contar sus víctimas.

\section{BIBLIOGRAFÍA CITADA}

BASCUÑán Rodríguez, Antonio (1994): "La regulación española de la coerción en el marco de la codificación penal europea”, Anuario de Derecho Penal y Ciencias Penales, Tomo No 47, Fasc./mes No 3: pp. 191-306.

BaUCElls i Lladós, Joan (2014): "Reflexiones críticas sobre el proyectado delito de hostigamiento", en Pérez Cepeda, Ana (Dir.) y Gorjón Barranco, María (Coord.), El proyecto de reforma del código penal de 2013 a debate (Salamanca, Ratio Legis), pp. 75-88.

Bronfman, Alan, Martínez, José, Núñez, Manuel (2012): Constitución Politica Comentada (Santiago, Abeledo Perrot-LegalPublishing Chile).

Cea Egaña, José (2012): Derecho Constitucional Chileno, Tomo II (Santiago, Ediciones Universidad Católica de Chile, segunda edición actualizada).

Comisión Constituyente (1975): “Actas Oficiales de la Comisión Constituyente. Sesión $106^{a ”}$ (13 de marzo de 1975). Disponible en https:/www.leychile.cl/Consulta/antecedentes_const_1980. Fecha de consulta 24 de julio de 2019.

Comisión Redactora del Anteproyecto de Código Penal 2018 (2018): "Entrega de Anteproyecto de Código Penal”. Disponible en:http://www.minjusticia.gob.cl/media/2018/10/Carta-entrega-Anteproyecto-de-C\%C3\%B3digo-Penal-2018.pdf. Fecha de consulta: 10 de diciembre de 2018.

Corn, Emanuele (2014): "La revolución tímida. El tipo de femicidio introducido en Chile por la Ley No 20.480 desde una perspectiva comparada", Revista de Derecho Universidad Católica del Norte, Año 21, No 2: pp. 103-136.

Dirección de Investigación Criminal de Carabineros de Chile (2017): "STalking. Informe Estratégico No 157/2017” (4 de diciembre de 2017).

Evans de la Cuadra, Enrique (1999): Los Derechos Constitucionales, Tomo I y II (Santiago, Editorial Jurídica de Chile, segunda edición actualizada). 
Figueroa, Rodolfo (2013): "El derecho a la privacidad en la jurisdicción de protección", Revista Chilena de Derecho, Vol. 40, No 3: pp. 859-889.

García Morillo, Joaquín (1995): El derecho a la libertad personal (Valencia, Tirant Lo Blanch).

García Pino, Gonzalo y Contreras Vásquez, Pablo (2014): Diccionario Constitucional Chileno, Cuaderno No 55 del Tribunal Constitucional (Santiago, Producciones Gráficas Ltda.).

Gavison, Ruth (1980): "Privacy and the Limits of Law", The Yale Law Journal, Vol. 89, No 3: pp. 421-471.

Gómez Castañeda, Eugenia (2015): "Las violencias de género y sus manifestaciones: una perspectiva jurídico normativa y social con particular referencia al femicidio", Temas de Mujeres revista del CEHIM, Año 11, No 11: pp. 24-52.

Guasp, Jaime, y Aragoneses, Pedro (2005): Derecho Procesal Civil, Tomo I (Navarra, Thomson Civitas, séptima edición).

Gutiérrez Castañeda, Ana (2013): "Acoso-Stalking: art. 173 ter", en Álvarez García, Francisco (Dir.) y Dopico Gómez-Aller, Jacobo (Coord.), Estudio Crítico Sobre el Anteproyecto de Reforma Penal de 2012 (Valencia, Tirant lo Blanch), pp. 581-588.

Lora MÁrquez, Mirian (2017): Estudio jurídico doctrinal del delito de acoso o stalking, Máster de Acceso a la Abogacía de la Universidad Internacional de La Rioja. Disponible en: https://reunir.unir.net/bitstream/handle/123456789/6520/LORA\%20 MARQUEZ\%2C\%20MARIAN.pdf?sequence=1 \&isAllowed=y. Fecha de consulta: 2 de marzo de 2019.

Maldonado Fuentes, Francisco (2018): “Amenazas y coacciones en el Derecho Penal Chileno", Politica Criminal, Vol. 13, No 25, Art. 1: pp. 1-41.

Martin Najera, Pilar (2016): "El nuevo delito de stalking del artículo 172 ter código penal”, Revista del Ministerio Fiscal, No 1: pp. 24-45.

Martínez Martínez, Patricia (2018): El delito de stalking, Trabajo fin de estudios, doble grado de administración y dirección de empresas y en derecho de la Universidad Pública de Navarra. Disponible en: https://academica-e.unavarra.es/bitstream/handle/2454/27438/79737TF Gmartinez.pdf?sequence=1\&isAllowed=y. Fecha de consulta: 23 de febrero de 2019.

Martínez de Pisón, José (1993): El derecho a la intimidad en la jurisprudencia constitucional (Madrid, Civitas).

Maugeri, Anna (2016): "El stalking en el Derecho comparado: la obligación de incriminación de la Convención de Estambul y técnicas de tipificación”, Revista Penal, No 38 : pp. 226-253.

Meloy, J. Reid y Gothard, Shayna (1995): "Demographic and clinical comparison of obsessional followers and offenders with mental disorders", The American Journal of Psychiatry, 152, 2: pp. 258-263.

Nogueira Alcalá, Humberto (2002): "La libertad personal y las dos caras de Jano en el Ordenamiento Jurídico Chileno", Revista de Derecho de la Universidad Austral de Chile, Vol. XIII: pp. 161-186.

Nogueira Alcalá, Humberto (2007): "El recurso de protección en el contexto del amparo de los Derechos Fundamentales Latinoamericanos e Internacionales", Revista Ius et Praxis, Año 13, No 1: pp. 75-134. 
Nogueira Alcalá, Humberto (2010): "La acción constitucional de protección en Chile y la acción constitucional de amparo en México", Revista Ius et Praxis, Año 16, No 1: pp. 219-286.

Novoa Monreal, Eduardo (1989): Derecho a la Vida Privada y Libertad de Información. Un conflicto de derechos (México, Siglo XXI Editores, cuarta edición).

Purcell, Rosmary, Pathé, Michele, y Mullen, Paul (2004): "Stalking: Defining and prosecuting a new category of offending", International Journal of Law and Psychiatry, No 27: pp. 157-169.

Roig Torres, Margarita (2018): "El delito de acoso (art. 172 ter CP) como modalidad de violencia de género. Comparativa con el "Nachstellung" del Derecho Aleman”, Estudios Penales y Criminológicos, Vol. XXXVIII: pp. 305-360.

RoyyaKers, Lamber (2000): “The Dutch approach to stalking Laws", California Criminal Law Review, Vol. 3, Issue 1, Art. 2: pp. 1-14.

Solove, Daniel (2009): Understanding Privacy (Harvard University Press).

Tapia Ballesteros, Patricia (2016): El nuevo delito de acoso o stalking (Madrid, WoltersKluwer).

U.S. Department of Justice: "Stalking in America: Findings from the National Violence Against Women Survey", Research in Brief by Patricia Tjaden \& Nancy Thoennes (April 1998). Disponible en: https://www.ncjrs.gov/pdffiles/169592.pdf. Fecha de consulta: 14 de diciembre de 2018.

U.S. Department of Justice: "Stalking Victims in the United States - Revised", Special Report by Shannan Catalano (September 2012). Disponible en: https://www.bjs.gov/ content/pub/pdf/svus_rev.pdf. Fecha de consulta: 15 de diciembre de 2018.

Varas Cicarelli, Germán (2012): "La orden de alejamiento en la violencia intrafamiliar y la relevancia del consentimiento de la víctima en su quebrantamiento", Revista Chilena de Derecho y Ciencia Política, Vol. 3, No 1: pp. 149-175.

Verdugo, Mario, Pfeffer, Emilio, Nogueira, Humberto (2005): Derecho Constitucional, Tomo I (Santiago, Editorial Jurídica de Chile, segunda edición).

Villacampa Estiarte, Carolina (2009a): "La introducción del delito de "atti persecutori" en el Código penal italiano. La tipificación del stalking en Italia”, Revista para el análisis del Derecho, Indret, No 3: pp. 1-29.

Villacampa Estiarte, Carolina (2009b): Stalking y derecho penal: relevancia jurídico-penal de una nueva forma de acoso (Madrid, Iustel).

Vivanco Martínez, Ángela (2006): Curso de Derecho Constitucional. Aspectos dogmáticos de la Carta Fundamental de 1980, Tomo II (Santiago, Ediciones Universidad Católica de Chile)

Warren, Samuel y Brandeis, Louis (1890): “The Right to Privacy”, Harvard Law Review, Vol. 4, No 5: pp. 193-220.

Westrup, Darrah y Fremouw, William (1998): "Stalking behavior: a literature review and suggested functional analytic assessment technology", Aggression and Violent Behavior, Vol. 3: pp. 255-274.

Zbairi Pardillo, Nabila (2018), El delito de stalking desde una perspectiva de género, análisis de la respuesta judicial-penal, Memoria para optar al grado de Derecho de la Universidad 
Autónoma de Barcelona. Disponible en: https://ddd.uab.cat/pub/tfg/2018/190859/ TFG_nzbairipardillo_1.pdf. Fecha de consulta: 1 de diciembre de 2018.

\section{NORMAS CITADAS}

Anteproyecto de Código Penal (22/10/2018). Disponible en: http://www.minjusticia. gob.cl/media/2018/10/Anteproyecto_de_C\%C3\%B3digo_Penal_2018.pdf. Fecha de consulta: 10 de diciembre de 2018.

Código Penal Alemán (STRafGesetzbuch) (15/05/1871).

Código Penal Austriaco (Strafgesetzbuch) (23/01/1974).

Código Penal Chileno (12/11/1874).

Código Penal Español (23/11/1995).

Código Penal italiano (Codice Penale) (19.10.1930).

Código Penal Portugués (Código Penal) (23/09/1982).

Constitución Política de la República de Chile (11/08/1980).

Convención Americana sobre Derechos Humanos (22/11/1969).

Ley de Protección contra el acoso del Reino Unido (Protection from Harassment Act 1997) $(21 / 03 / 1997)$.

LEY No 18.168 (02/10/1982), Ley General de Telecomunicaciones.

LEY No 19.223 (07/06/1993), Tipifica figuras penales relativas a la informática.

LEY No 20.066 (07/10/2005), Establece ley de violencia intrafamiliar.

Ley Orgánica No 1/2015 (30/03/2015), Modifica la Ley Orgánica 10/1995, de 23 de noviembre, del Código Penal Español.

Mensaje No 393-366 (09/03/2019), Proyecto de ley que sanciona el acoso por cualquier medio. Disponible en: https://www.camara.cl/pley/pley_detalle.aspx?prmID=13002\&p rmBoletin=12473-07. Fecha de consulta: 16 de marzo de 2019.

Pacto Internacional de Derechos Civiles y Políticos (16/12/1966)

\section{JURISPRUDENCIA CITADA}

ACCIÓN DE INAPLICABILIDAD POR INCONSTITUCIONALIDAD DE JORGE WASHINGTON SEPÚLVEDA ÁLVARez Respecto del artículo 365 del Código Penal, en los autos RUC 0800242317 - 1, RIT 1287 - 2008 sustanCIADOS ANTE EL JUZGADO DE GARANTÍA DE CAÑETE (2011): Tribunal Constitucional chileno, Rol No 1683-10, 4 de enero de 2011. Disponible en: https:// www.tribunalconstitucional.cl/sentencias. Fecha de consulta 25 de julio de 2019.

Chaparro Álvarez y Lapo ÍñIgUez. vs. ECUAdor. Corte Interamericana de Derechos Humanos. Sentencia del 21 de noviembre de 2007. Serie C No. 170. Disponible en: http:// www.corteidh.or.cr/docs/casos/articulos/seriec_170_esp.pdf. Fecha de consulta: 23 de noviembre de 2018.

Comercial LAMA Limitada con SerVicio de Impuestos Internos VIII DR CONCEPCión (2019): Corte Suprema, 18 de febrero de 2019 (casación en la forma y en el fondo en materia tributaria y aduanera), ROL 24.757-2018. Disponible en: https://www.pjud.cl/ consulta-de-causas2. Fecha de consulta: 25 de julio de 2019. 
Constructora el Medano Limitada contra Municipalidad de Santiago (2018): Corte Suprema, 4 de junio de 2018 (casación en la forma y en fondo por reclamación de ilegalidad municipal), Rol 1.614-2017. Disponible en: https://www.pjud.cl/consulta-decausas2. Fecha de consulta: 25 de julio de 2019.

E. CON L. (2018): Juzgado de Garantía de Temuco, 4 de julio de 2018 (denuncia por amenazas simples), RIT 6471-2018. Disponible en: https://www.pjud.cl/consulta-decausas2. Fecha de consulta: 26 de noviembre de 2018.

E. CON O. (2018): Juzgado de Familia de Temuco, 9 de agosto de 2018 (denuncia por violencia intrafamiliar), RIT F-1113-2018. Disponible en: https:/www.pjud.cl/consultade-causas2. Fecha de consulta: 26 de noviembre de 2018.

Hassen con Servicios y Administración de CRÉditos Comerciales Presto S.A. (2016): Corte de Apelaciones de Santiago, 2 de junio de 2016 (Recurso de Protección de garantías fundamentales), ROL 34.199-2016. Disponible en: https://www.pjud.cl/consulta-decausas2. Fecha de consulta: 8 de diciembre de 2018.

Karstegl con BANCo Falabella (2018): Corte de Apelaciones de Santiago, 14 de septiembre de 2018 (Recurso de Protección de garantías fundamentales), ROL 46.917-2018. Disponible en: https://www.pjud.cl/consulta-de-causas2. Fecha de consulta: 8 de diciembre de 2018.

L. CON E. (2019): Corte de Apelaciones de Valdivia, 14 de enero de 2019 (Recurso de Protección de garantías fundamentales), ROL 2261-2018. Disponible en: https:/www. pjud.cl/consulta-de-causas2. Fecha de consulta: 22 de noviembre de 2018.

Muñoz con Empresa Nacional de Telecomunicaciones S.A. (2017): Corte Suprema, 2 de octubre de 2017 (Recurso de Protección de garantías fundamentales), ROL 99.8622016. Disponible en: https://www.pjud.cl/consulta-de-causas2. Fecha de consulta: 8 de diciembre de 2018.

Olivares con Ripley Chile S.A. (2017): Corte de Apelaciones de Santiago, 13 de septiembre de 2017 (Recurso de Protección de garantías fundamentales), ROL 46.737-2017. Disponible en: https://www.pjud.cl/consulta-de-causas2. Fecha de consulta: 11 de diciembre de 2018.

REQUERIMIENTO DE INAPLICABILIDAD POR INCONSTITUCIONALIDAD PRESENTADO POR JOSÉ IGNACiO LARA Ostornol RESPECTO DEL INCISO FINAL DEL ARTÍCULO 40 DE LA LEY No 18.287, EN los aUtos Rol No 366-2010 SOBRE RECURSO DE HECHO INTERPUESTO ANTE LA CORTE DE Apelaciones de VALParaíso (2012): Tribunal Constitucional chileno, Rol No 1804-10, 29 de marzo de 2012. Disponible en: file://C:/Users/Edmundo\%20Borel/Downloads/39637\%20(1).pdf. Fecha de consulta: 23 de julio de 2019.

REQUERIMIENTO DE INCONSTITUCIONALIDAD PRESENTADO POR UN GRUPO DE SENADORES RESPECTO DE LAS NORMAS QUE INDICA CONTENIDAS AL PROYECTO DE LEY QUE MODERNIZA EL SISTEMA DE RELACIONES LABORALES, INTRODUCIENDO MODIFICACIONES AL Código dEL TRABAjo, CORRESPONDIENTE AL BOLETÍN No 9835-13 (2016): Tribunal Constitucional chileno, Rol No 3016-16, 9 de mayo de 2016. Disponible en: https://www.tribunalconstitucional.cl/ sentencias. Fecha de consulta: 7 de febrero de 2019. 
VAlls y otros con Red De TELEVISión ChILEVISIÓN S.A. (2019): Corte Suprema, 24 de enero de 2019 (casación en el fondo en autos sobre demanda de indemnización de perjuicios), ROL 38.037-2017. Disponible en: https:/www.pjud.cl/consulta-de-causas2. Fecha de consulta: 7 de enero de 2019. 
